\title{
UPAYA PENGENDALIAN MUTU HARUM MANIS BAKERY DALAM MENCIPTAKAN KEPUASAN PELANGGAN \\ (Studi Pengendalian Mutu Harum Manis Bakery di Lampung)
}

\author{
Dwita Dharma Prastiwi ${ }^{1}$ dan Intan Septiana Sari ${ }^{2}$ \\ ${ }^{12}$ Mahasiswa STP AMPTA Yogyakarta \\ 1Email : dwitadharma@gmail.com \\ 2Email : intanseptianasari@gmail.com
}

\begin{abstract}
ABSTRAC
Harum Manis is a bakery (bakery) located in Pringsewu, Lampung. This bakery has been established since the 1990's. This business started from a very small business, then over time and the growing innovation issued by Harum Manis Bakery makes this business growing and progressing. In addition, the thing that makes this store survive is the quality and service provided. Harum Manis always put quality in every product. So do not be surprised if this business still survive for more than 20 years. The purpose of this study is to analyze how the Harum Manis Bakery effort in maintaining the quality of its products for customer satisfaction. Based on sample determination method, the sample used is three respondents. From the results of analyzes conducted the quality of Harum Manis Bakery provided starting from the selection of materials, equipment used, cleanliness, price and taste significantly affect customer satisfaction. This study used qualitative research methods.
\end{abstract}

Keyword: Harum Manis, Bakery, Quality, Customer Satisfaction

\begin{abstract}
ABSTRAC
Harum manis adalah sebuah bakery (toko roti) yang terletak di Pringsewu, Lampung. Toko roti ini sudah berdiri sejak tahun 1990-an. Usaha ini berawal dari sebuah usaha yang sangat kecil, kemudian seiring berjalannya waktu dan semakin berkembangnya inovasi yang di keluarkan oleh Harum Manis Bakery membuat usaha ini semakin berkembang dan maju. Selain itu juga hal yang membuat toko ini bertahan adalah mutu serta pelayanan yang diberikan. Harum Manis selalu mengutamakan mutu dalam setiap produknya. Jadi tidak heran jika usaha ini masih bertahan hingga lebih dari 20 tahun. Dengan begitu tujuan dari penelitian ini adalah untuk menganalisi bagaimana upaya Harum Manis Bakery dalam menjaga mutu produknya untuk kepuasan pelanggan. Berdasarkan metode penentuan sampel maka sampel yang digunakan adalah tiga responden. Dari hasil analisis yang dilakukan mutu yang diberikan Harum Manis Bakery mulai dari pemilihan bahan, peralatan yang digunakan, kebersihan, harga dan rasa berpengaruh secara signifikan pada kepuasan pelanggan. Penelitian ini menggunakan metode penelitian kualitatif.
\end{abstract}

Kata kunci : Harum Manis , Bakery, Mutu , Kepuasan Pelanggan 


\section{PENDAHULUAN}

Pariwisata telah terbukti mampu menjadi solusi dalam menopang ekonomi Negara Indonesia. Banyak industri pariwisata di berbagai daerah telah terbukti mampu menciptakan lapangan kerja, menciptakan peluang usaha baru, meningkatkan pendapatan daerah dan kesejahteraan sosial-ekonomi pada umumnya (Hermawan, 2016a; dan Hermawan, 2016b)

Trend dalam ekonomi global saat ini, usaha jasa mendominasi ekonomi global. Usaha jasa terbukti mampu menyumbangGross Domestik Bruto (GDP) global terbesar.Industri jasa termasuk pariwisata dan hospitality industrymenyubang sebesar 64\% GDP Global, diikuti industri manufaktur 32\%, kemudian sisanya sebanyak $4 \%$ disumbang industri pertanian/ agriculture(Lovelock, 2011).

Perkembangan bisnis di industri pastry and bakery terus berkembang kearah yang lebih baik. hal ini terlihat sejalan dengan pesatnya perkembangan dunia bisnis pastry and bakery, dimana semakin banyak pelaku usaha membuka dan mengembangkan bisnis mereka, baik industry kecil maupun industry besar. Banyaknya bisnis pastry and bakery menyebabkan terjadinya persaingan yang semakin kuat di bidang usaha itu. Terlebih untuk belajar membuat aneka olahan pastry and bakery lebih mudah para pemula tidak perlu sekolah khusus untuk belajar membuat olahan pastry and bakery.

Hal tersebut didukung oleh makan kue telah menjadi salah satu lifestyle bagi masyarakat. Hampir sebagian besar masyarakat menjadikan pastry and bakery sebagai makanan untuk sarapan maupun makanan penutup. Selain itu semua kalangan kini banyak mendatangi pastry and bakery untuk memenuhi kebutuhan mereka terhadap kue dan roti. Dimulai untuk dikonsumsi sehari hari, kue ulang tahun, kue pernikahan, dan sebagainya.

Saat ini, konsumen dalam menilai sebuah produk sangat memperhatikan mutu/kualitas, manfaat, harga, dan fungsi yang diberikan oleh produk itu sendiri. Dengan begitu, pengusaha bisnis pastry and bakery tetap terus memperhatikan apa yang diinginkan konsumennya.

Seiring perkembangan jaman saat ini, tak sedikit pengusaha pastry and bakery yang masih kurang memperhatikan kualitas dari produk yang dijual, baik dari segi rasa, pengemasan, kebersihan, pilihan bahan, serta peralatan yang digunakan dalam proses produksinya. Dengan adanya para pengusaha pastry and bakery yang tidak memperhatikan kualitasnya membuat masyarakat selaku konsumen menjadi lebih selektif karena tak sedikit pula produsen atau pengusaha pastry and bakery yang menggunakan bahan dengan kualitas yang biasa bahkan jauh dari standar untuk membuat produk mereka.

Menurut Philip Kotler dan Kevin Lane Keller yang dikutip dari buku Manajemen Pemasaran mengatakan bahwa Kepuasan Konsumen adalah perasaan senang atau kecewa seseorang yang muncul setelah membandingkan kinerja (hasil) produk yang dipikirkan terhadap kinerja yang diharapkan (2007:177).

Sedangkan menurut (Umar, 2005:65). pengertian kepuasan pelanggan ialah adalah tingkat perasaan konsumen setelah membandingkan antara apa yang dia terima dan harapannya Seorang pelanggan, jika merasa puas dengan 
nilai yang diberikan oleh produk atau jasa, sangat besar kemungkinannya menjadi pelanggan dalam waktu yang lama.

\section{KAJIAN LITERATUR Pengendalian Mutu}

Mutu merupakan suatu kondisi dinamis yang berhubungan dengan produk, jasa, manusia, proses dan lingkungan yang memenuhi atau melebihi harapan. Difinisi konvensional dari kualitas biasanya menggambarkan karakteristik langsung dari suatu produk, seperti performansi, keandalan, mudah dalam penggunaan dan estetika.

keuntungan yang dicapai dengan menghasilkan produk atau pelayanan bermutu yaitu peningkatan pasar (market gain) dan peghematan biaya (cost saving). Mutu produk atau pelayanan yang meningkat akan membuat produk (baik barang maupun jasa) tersebut makin dikenal sehingga permintaan pasar meningkat dan keuntungan perusahaan juga meningkat. Mutu produk yang meningkat akan menurunkan biaya produksi atau service. cacat produk tentu akan mengakibatkan penggantian ulang (rework) yang membutuhkan tambahan biaya material, biaya tenaga kerja, listrik,dll, yang mengurangi keuntungan perusahaan.

Alasan untuk memproduksi produk berkualitas karena produk berkualitas prima memang akan lebih atraktif bagi konsumen, bahkan akhirnya dapat meningkatkan volume penjualan. Tetapi lebih dari itu, produk berkualitas mempunyai aspek penting lain. Konsumen yang membeli produk berdasarkan mutu, umumnya mereka mempunyai loyalitas produk yang besar dibandingkan dengan konsumen yang membeli berdasarkan orientasi harga. Selain itu, bersifat kontradiktif dengan cara berfikir bisnis tradisional, ternyata bahwa memproduksi barang bermutu tidak secara otomatis lebih mahal dengan memproduksi barang bermutu rendah. Banyak perusahaan menemukan (discovery) bahwa memproduksi produk bermutu tidak harus berharga lebih mahal. Mengapa? Fakta menunjukkan, bahwa cara (methods) berproduksi untuk menghasilkan produk bermutu tinggi secara simultan meningkatkan produktivitas, antara lain mengurangi penggunaan bahan (reduce materials usage) dan mengurangi biaya.

Menjual barang tidak bermutu, kemungkinan akan banyak menerima keluhan dan pengembalian barang dari konsumen. Atau biaya untuk memperbaikinya (after sales services) menjadi sangat besar, selain memperoleh citra tidak baik. Belum lagi kecelakaan ydiderita oleh konsumen akibat pemakaian produk yang bermutu rendah. Konsumen tersebut mungkin akan menuntut ganti rugi melalui pengadilan(prihatno,2017). 


\section{Pastry and Bakery}

Pastry / patiseri adalah salah satu pengetahuan dalam pengolahan dan penyajian makanan, terutama proses dan sekarang berbagai jenis kue . Patiseri berasal dari bahasa Prancis "Patisserie" yang berarti kue-kue. Patiseri dengan demikian dapat diartikan sebagai ilmu yang mempelajari tentang seluk beluk kue kue kontinenl baik, oriental dan kue Indonesia mulai dari persiapan, pengolahan sampai dengan presentasi. Pastry di dunia perhotelan adalah salah satu departemen foodEbeverage yang produknya bertugas membuat kue dan dessert. Bakery saat ini digunakan untuk keperluan sarapan, coffe break, makan siang dan makan malam.

Menurut Adjab Subagjo(2007 :87) dalam bukunya Management Pengolahan Kue dan Roti. "Pastry adalah bagian dari food product atau kitchen yang ada di dalam lingkup food and beverage department yang mempunyai tugas dalam pembuatan dessert atau makanan penutup, snack atau makanan pengirim minuman, seperti kue dan roti. Menurut Bartono(2005:164) dalam bukunya Food Product Management di Hotel dan Restoran mengatakan bahwa "pastry adalah merupakan bagian dari dapur yang memproduksi khususnya berbagai jenis roti, cake, dan dessert.

Dalam pengertian diatas dapat disimpulkan pastry adalah bagian dari dapur yang bertugas khusus untuk membuat roti, cake, dan dessert. Pastry atau "Patisserie" di hotel memiliki dua bagian pokok, yaitu bagian panas yang memproduksi cake dan bagian dingin yang memproduksi dessert. Produk pastry and bakery yang berkualitas memiliki ukuran keberhasilan yaitu melalui food test oleh pihak calon pelanggan. Food test terhadap produk pastry and bakery antara lain menyangkut :

1. Rasa makanan harus enak dan bervariasi,

2. Tingkat kebersihannya,

3. Besar porsi,

4. Kemasan,

5. Kemampuan memproduksi dalam hitungan banyak,

6. Ketahanan makanan,

7. Harga,

8. Jaminan ketepatan waktu.

\section{Kepuasan Pelanggan}

Kepuasan wisatawan adalah tingkat perasaan seseorang setelah membandingkan kinerja atau hasil yang dirasakan dibandingkan dengan harapannya (Kotler dan Makens, 1999).

Dalam bukunya yang lain, Kotler (2002) mendefinisikan kepuasan sebagai perasaan senang atau kecewa seseorang yang muncul setelah membandingkan antara persepsi/ kesannya terhadap kinerja (atau hasil) suatu produk dan harapan-harapannya. Kepuasan tentang produk dibandingkandengan harapan wisatawan sebelum menikmati produk hospitality dan pariwisata. 
Kepuasan telah begitu lama menjadi perhatian para ahli pemasaran, karena wisatawan yang puas akan cenderung loyal terhadap suatu produk atau jasa. Kepuasan pelanggan merupakan faktor penentu, apakah suatu bisnis akan berkelanjutan atau tidak (Hermawan, 2017a). Begitu juga dalam usaha hospitality dan pariwisata, upaya untuk menciptakan kepuasan wisatawan juga menjadi perhatian serius para pengelola usaha.

\section{METODE PENELITIAN}

Artikel ini ditujukan untuk menggali lebih dalam tentang "Upaya Pengendalian Mutu Harum Manis Bakery Dalam Menciptakan Kepuasan Pelanggan”.

Metode penelitian yang digunakan merupakan metode desktiptif kualitatif. Selain itu pendekatan kualitatif digunakan untuk memperoeh gambaran diskriptif yang lebih luas mengenai fenomena yang diamatai (Moleong, 2004). Karena, pendekatan kualitatif dipandang mampu menggali pemaknaan terhadap fenomena secara lebih mendalam (Creswell, 1994).

Lokasi penelitian di "Harum Manis Bakery Pringsewu, Lampung". Sedangkan waktu pelaksanaanya telah dilakukan pada 2 April-4 April 2018.

Sebagai jaminan kevalidan data, dilakukan kroscek menggunakan 3 sumber data, biasa dikenal sebagai triangulasi(Hermawan, 2017b). Responden yang menjadi narasumber utama adalah Ibu Suwarti selaku pemilik, Intan Septiana Sari selaku anak pemilik, dan Dwi Retno selaku pelanggan tetap Harum Manis Bakery.

Teknik pecarian data digunakan adalah wawancara, pengamatan, serta kegiatan dokumentasi berupa pencatatan, perekaman, dan foto-foto.

Analisis data digunakan mengacu pada kaidah-kaidah metodologi kualitatif secara umum seperti reduksi, penyajian data, verifikasi serta triangulasi data (Moleong, 2004; dan Brahmanto, Hermawan, \& Hamzah, 2017)

\section{HASIL DAN PEMBAHASAN}

Kami melakukan wawancara dengan ibu suwarti, mengenai hal apa saja yang ia lakukan sebelum memulai membuat produknya serta kegiatan sehari-harinya

1. Menghubungi supplier

Menghubungi supplier biasanya dilakukan oleh ibu suwarti jika stok di gudang sudah menipis, agar tidak terjadi kehabisan bahan disaat sedang melakukan produksi. Supplier yang di pilih oleh ibu Suwarti juga telah menjadi langganan usahanya, karena sudah memasuki kriteria supplier yang di tetapkan oleh ibu Suwarti baik dari sisi harga dan kualitas.

2. Menyiapkan peralatan

Persiapan peralatan dilakukan sebelum memulai proses produksi, tahapan ini ibu suwarti lakukan agar pada saat prose produksi tidak terlalu membuang waktu untuk mencari alat-alat lagi (untuk mempermudah proses produksi)

3. Menyiapkan bahan 
Persiapan bahan di lakukan setelah selesai melakukan penyiapan peralatan hal ini dilakukan tidak bersamaan dengan proses penyiapan peralatan guna menghindari terjadinya salah penyiapan. Bahan-bahan yang dipilih oleh ibu Suwarti adalah bahan-bahan dengan kualitas yang baik, hal ini ia lakukan agar kualitas produk yang ia produksi tetap terjaga.

4. Proses pra-produksi

Proses pra produksi di lakukan jika, proses persiapan bahan dan peralatan telah selesai dilakukan. Sebelum melakukan proses produksi Ibu Suwarti terlebih dahulu mencuci tangannya guna memastikan kebersihan serta tak lupa ia juga membersihkan tempat yang akan dilakukan prosesnya. Pada proses ini ibu Suwarti juga melakukan scalling terhadap bahan-bahan yang akan di pakai untuk di produksi.

5. Proses Produksi

Proses produksi adalah proses pembuatan produk yang di jual oleh ibu Suwarti, pada proses ini biasanya ibu Suwarti membuat beberapa produk baik yang untuk dijual secara langsung, pesanan pelanggan, maupun produk yang dititipkan di toko-toko kue di daerah Pringsewu maupun di luar Pringsewu. Proses produksi biasanya dilakukan sekitar pukul enam pagi sampai pukul tujuh sore.

6. Proses Pasca Produksi

Pada proses ini Ibu Suwarti melakukan pengecekan atas produk yang telah di buat, selain itu juga Ibu Suwarti memisahkan produk-produknya tersebut ke tiga bagian pertama produk yang akan di display, kedua produk pesanan, ketiga produk yang akan di titipkan kepada pedagang lain.

\section{KESIMPULAN}

Dengan demikian dapat kami simpulkan bahwa perkembangan industri makanan khususnya bagian pastry and bakery mulai berkembang dengan sangat pesat. Semakin maraknya usaha pastry and bakery yang bermunculan semakin memperketat tingkat persaingan antar pengusaha. Tidak jarang juga usaha yang sudah dirintis sekian lama hancur karena pesaing yang lebih inovatif dalam pengembangan usaha mereka. Selain itu juga kualitas atau mutu sangatlah berperan penting terhadap berdirinya serta bertahannya suatu usaha. Karena jika usaha yang didirikan tidak memberikan mutu yang baik maka akan membuat pelanggan menjadi berpindah ke perusahaan lain. Selain itu juga mutu yang baik akan membuat konsumen puas terhadap produk yang kita berikan. 


\section{DAFTAR PUSTAKA}

Ariani, D. W. (2009). Manajemen Operasi Jasa. Yogyakarta: Graha Ilmu.

Bartono, P.H dan Ruffino, E.M. 2005. Food Product Management di Hotel dan Restoran. Yogyakarta: C.V Andi Offset

Brahmanto, E., Hermawan, H., \& Hamzah, F. (2017). Strategi Pengembangan Kampung Batu Malakasari sebagai Daya Tarik Wisata Minat Khusus.

Creswell, J. W. (1994). Research Design-Qualitative, Quantitative, and Mixed Method. London: SAGE Publications.

Echols, J. M. (1976). Kamus Inggris-Indonesia= An English-Indonesian dictionary/oleh John M. Echols dan Hassan Shadily. Cornell University Press PT Gramedia.

Fiifi, A. (2017). Hotel Resort dengan Pendekatan Arsitektur Ekologis di Batu Malang. Universitas Sebelas Maret.

Hermawan, H. (2016a). Dampak Pengembangan Desa Wisata Nglanggeran Terhadap Ekonomi Masyarakat Lokal. Jurnal Pariwisata, 3(2), 105-117.

Hermawan, H. (2016b). Dampak Pengembangan Desa Wisatanglanggeran Terhadap Sosial Budaya Masyarakat Lokal. In Seminar Nasional Ilmu Pengetahuan dan Komputer (SNIPTEK) Nusa Mandiri (pp. 426-435). Bandung Indonesia: $\quad$ SNIPTEK $2016 . \quad$ Retrieved from http://konferensi.nusamandiri.ac.id/prosiding/index.php/sniptek/issue/ view $/ 1 \% 0 \mathrm{~A}$

Hermawan, H. (2017a). Pengaruh Daya Tarik Wisata, Keselamatan dan Sarana Wisata Terhadap Kepuasan serta Dampaknya terhadap Loyalitas Wisatawan: Studi Community Based Tourism di Gunung Api Purba Nglanggeran. Wahana Informasi Pariwisata : Media Wisata, 15(1), 562-577.

Hermawan, H. (2017b). Pengembangan Destinasi Wisata pada Tingkat Tapak Lahan dengan Pendekatan Analisis SWOT. Jurnal Pariwisata, 4(2), 64-74.

Hermawan, H., Brahmanto, E., \& Hamzah, F. (2018). Pengantar Manajemen Hospitality. Jawa Tengah: PT Nasya Expanding Management.

Hershberger, M. (1999). A Christian view of hospitality: Expecting surprises. Herald Press.

Kotler, P. (2002). Manajemen Pemasaran, terjemahan Hendra Teguh, edisi Millenium, cetakan pertama (1st ed.). Jakarta: Prenhalindo.

Kotler, P., \& Makens, J. C. (1999). Marketing for Hospitality and Tourism, 5/e. Pearson Education India.

Kotler, Philip Dan Kevin Lane Keller. 2007. Manajemen Pemasaran. Edisi Kedua Belas. Indeks : Jakarta Lovelock, C. (2011). Services Marketing, 7/e. Pearson Education India.

Mill, R. C. (1990). Tourism: the international business. Prentice-Hall International, Inc.

Moleong, L. (2004). Metode Penelitian Kualitatif. Bandung: Remaja Rosda Karya.

Nouwen, H. J. M. (1998). Reaching out: A Special edition of the spiritual classic including Beyond the Mirror. Zondervan.

Prihatno. (2017). Modul Kuliah Pengendalian Mutu. Yogyakarta: STP AMPTA Yogyakarta.

Saleh, F., \& Ryan, C. (1991). Analysing service quality in the hospitality industry 
using the SERVQUAL model. Service Industries Journal, 11(3), 324-345.

Subagyo, adjab. (2007) Manajemen Pengolahan Kue \&Roti. Yogyakarta: Graha.

Sulastiyono, A. (2011). Manajemen penyelenggaraan hotel: seri manajemen usaha jasa sarana pariwisata dan akomodasi. Bandung: Alfabeta.

Umar, Husein. 1997. Study Kelayakan Bisnis. Edisi Ketiga. Gramedia Pustaka Utama : Jakarta

Webster, K. (2000). Environmental management in the hospitality industry: a guide for students and managers. Cengage Learning EMEA.

Yoeti, O. A. (2004). Strategi pemasaran hotel. Jakarta: Gramedia Pustaka Utama.

Zeithaml, V. A., \& Bitner, M. J. (1996). Services Marketing. New York: McGrawHill. New York: McGrawHill.

\section{PROFIL PENULIS}

Dwita Dharma Prastiwi dan Intan Septiana Sari, merupakan mahasiswi sarjana terapan (D4) di Sekolah Tinggi Pariwisata jurusan Pengelolaan Perhotelan. 